\title{
EL PROBLEMA DE LA FUNDAMENTACION DE LOS DERECHOS HUMANOS
}

\author{
Laura Mues de Schrenk \\ UNIVERSIDAD DE GEORGETOWN
}

La discusión acerca de la fundamentación de los derechos humanos en la modernidad ${ }^{1}$ ha arrancado de la construcción hipotética de un "estado natural" o "estado de naturaleza", del que se supone que es anterior a la formación de cualquier Estado civil jurídico. Pero dicho estado natural no es prehistórico, sino que es representado como la base natural sobre la cual ha de formarse el derecho civil en sus diversas formas, con su legislación positiva respectiva. En ese estado natural, se ha pensado, existe ya el derecho natural en los individuos, de modo que los seres humanos tienen ya por naturaleza, ciertos derechos que deben ser respetados por todos los demás. Dichos derechos, por pertenecer a la naturaleza humana, son inalienables. El que esto es así parece incuestionable para la mayoría de nosotros. Sin embargo, parece no serlo para aquellos que violan esos derechos, los verdugos que torturan y asesinan - como sucede en nuestros días en casi toda Latinoamérica-, razón por la cual me parece que es necesario fundamentar su existencia. Para hacerlo, quisiera discutir aquí:

1. los derechos naturales de que habla la tradición liberal desde Locke, para examinar si, en efecto, tales derechos son inherentes a la naturaleza humana, y

2. quisiera examinar si el reconocimiento de esos derechos puede ser fundamentado mediante una teoría determinada.

Parto aquí de la tradición liberal que nació del espíritu de Locke, porque la interpretación y la discusión de nuestros días en torno a esos

1 Este trabajo fue leido como ponencia en el I Congreso Nacional de Filosofía en la ciudad de Guanajuato, en 1981. Salvo algunas correcciones aclaratorias, dejo el texto como habla sido redactado originalmente. Este trabajo no pretende ser un estudio exhaustivo de los principios filosóficos de Locke. El que Locke haya establecido, descrito y tratado de fundamentar los derechos básicos de que parto aqui, no significa que con Locke se haya iniciado ni agotado la discusión acerca del problema. El mérito de Locke radica, en cambio, en haber tematizado estos derechos en la conciencia de la filosoffa, razón por la cual no podrán ser ya negados a los humanos en el proceso histórico, político y social del individuo. 
derechos se hace inspirar por ella, asi sucede, por ejemplo, en Hart, ${ }^{2}$ Dworkin, ${ }^{3}$ Nozick ${ }^{4} y$, entre los economistas, Milton Friedman. ${ }^{5}$

Pero antes quisiera hacer notar que el término "derechos humanos" no fue usado sino por los primeros enciclopedistas franceses del siglo xviII, y unas décadas más tarde por los filósofos alemanes Kant, Fichte, Hegel y Marx en sus trabajos críticos. En la tradición anglosajona de la modernidad, en cambio, se habló de "derechos naturales" desde Hobbes, y aun en nuestros días muchos pensadores de habla inglesa usan el término natural rights. ${ }^{6}$ En este término se expresa la interpretación de que esos derechos lo son por naturaleza. Y se piensa asf porque le son dados al individuo con su vida biológica. Por "naturaleza" se ha entendido, en este contexto, el conjunto de fenómenos y acontecimientos que ocurren ciegamente - sin intervención de la actividad humana- por sí mismos, con una regularidad constante y predecible, establecida por ciertas leyes.?

Locke parte de la premisa inicial de que el estado de naturaleza es un estado de igualdad natural entre todos los individuos, de modo que ninguno tiene sobre otros más derechos, poder, ni jurisdicción alguna. De acuerdo con esto, el estado natural debería ser entendido como un estado de igualdad social, en que nadie puede ni debe dictarle a otros un reglamento para su conducta; con esto, todos y cada uno de los individuos puede siempre hacer lo que le plazca. La igualdad de los humanos se basa en el hecho de que por naturaleza todos están dotados de razón, hombres y mujeres por igual. Mediante la razón, todos son capaces de conocer la "ley de la naturaleza", de la cual Locke nos dice que "...nos enseña, a toda la humanidad que la consulte, que, siendo todos iguales e independientes, nadie deberá dañar a otro en su vida, salud, libertad o posesiones", ${ }^{8}$ o sea que la ley de la naturaleza dicta que no debemos invadir los derechos de otros. Asf, según Locke, en el

2 H. L. A. Hart, The Concept of Law.

3 D. Dworkin, Taking Rights Seriously.

- R. Nozick, State, Anarchy and Utopia.

s M. Friedman, Programa de TV, To Be Free, 1980.

- La discusión acerca del derecho natural como idea, aunque no como término, se inicia ya con Platón. Sin embargo, quien introduce la terminologia para expresar esa idea en la tradición occidental es Cicerón en su diálogo De legibus. $\mathrm{Y}$ hay que re. cordar que Locke está sumergido en las ideas políticas de su siglo, ideas influidas por Francisco de Victoria, Grotius y Puffendorf.

7 Tengo conciencia de la ambigüedad del término "naturaleza". Los filósofos han tenido grandes dificultades en definirlo, dado que es uno de los conceptos más generales. Bajo el concepto "naturaleza" se pueden subsumir todos los conceptos generales que nombran objetos empíricos. Y cuando los filosofos han tratado de definirlo, han recurrido a su opuesto, por ejemplo al concepto "dios" o "espiritu"; o al concepto "cultura". Pero aquí no quisiera discutir este concepto; baste con decir que he asumido el significado que le da Kant en los Prolegómenos.

8 J. Locke, Second Treatise on Government, II, núm. 6. 
estado natural la ley de la naturaleza se da como ley moral, dado que es la moral la que dicta leyes para los deberes u obligaciones ante los otros. Sin embargo, si la ley moral fuera una ley de la naturaleza, como dice Locke, los individuos la seguirían ciegamente, como los planetas siguen su curso, sin necesidad de conocerla.

Los derechos naturales que los individuos tienen ya en ese estado natural son, pues, según Locke y sus sucesores, el derecho a la vida y a la salud, a la libertad y a la propiedad. Éstos son derechos fundamentales o básicos, de los cuales se derivan otros derechos secundarios.

Discutiremos ahora cada uno de ellos.

a) El derecho a la vida y a la salud. Este derecho, dice Locke, implica también el derecho a adquirir los medios materiales necesarios para sostener vida y salud. Hasta aqui muy bien. Locke no enumera cada uno de ellos, pero siendo el ser humano un ser histórico, si reflexionamos acerca de los medios que, por naturaleza, en nuestros días son necesarios para conservar la vida, entonces en el derecho a la vida están incluidos, como su condición necesaria, el derecho al alimento suficiente y saludable, el derecho a la vivienda en condiciones higiénicas, el derecho a una educación vocacional o profesional, a los medios para adquirir tal educación, el derecho a tener un empleo que sea fuente de ingresos para adquirir los bienes materiales suficientes con qué sostener la vida y la salud. Pero para ello es también indispensable respirar aire puro, beber agua no contaminada, no estar sujeto al infernal ruido de los aparatos de la tecnología moderna, etcétera.

Sin embargo, si el derecho a la vida es un derecho natural de cada uno de los individuos, también tendrá que serlo el derecho a recibir protección y seguridad material contra todo posible agresor que dañe la vida y salud, para que esos derechos puedan ser garantizados como derechos. De acuerdo con la premisa inicial, esos derechos los tienen, o mejor dicho, los deberian tener todos los humanos por igual.

Ahora bien, ¿qué significa que el derecho a la vida -y con él los derechos derivados de aquél- inherente a la naturaleza humana? Evidentemente no se trata de ciertas propiedades inherentes a su naturaleza, como lo son la respiración, la circulación, etcétera -elementos sine qua non de la vida humana misma; pero tampoco se trata de ciertos acontecimientos naturales, como lo son, por ejemplo, el nacimiento y la reproducción; ni tampoco son ciertas características descriptivas mediante las cuales se define su naturaleza, como lo sería el decir que el ser humano es un bipedo implume. Tanto la respiración como la circulación son datos empíricos inherentes a la naturaleza humana en vida, como son datos empíricos el nacimiento y la reproducción; y empírico es también el constatar que el ser humano es, en efecto, un bipedo im- 
plume. De allí que del derecho no se pueda decir que es inherente a la naturaleza humana. Si lo fuera, sería un concepto empírico, y no sería necesario establecerlo como tal, distinto a la vida misma; mencionarlo sería una redundancia. Sin embargo, así se piensa, los humanos nacen con esos derechos, aun cuando otros no los conozcan ni los reconozcan, y por eso los violen de la manera más salvaje.

Pero hay otro elemento más. En el concepto derecho está implicada otra noción que tampoco es inherente a la naturaleza humana y que por eso tampoco es un concepto empírico. Esta es la noción de deber o de obligación. Locke explica que la "ley de la naturaleza" - cognoscible mediante la razón - nos enseña "... a toda la humanidad que la consulte, que, siendo todos iguales e independientes, nadie deberá dañar a otro en su vida, salud..." Al usar el término "deberá". Locke implica dos cosas diferentes: i) que en la naturaleza existen -además de los fenómenos de la naturaleza y las leyes que ciega y necesariamente los rigen- otras leyes, que no describen ni explican los fenómenos de la naturaleza; ii) para que estas leyes se cumplan, los humanos deben actuar no ciegamente como suceden los fenómenos de la naturaleza, sino consultando la razón. La razón le enseñará, a todo humano que la consulte, que hay una ley que le dicta el deber o la obligación de regir su conducta de tal manera que no lesione los derechos de otros. La noción de deber o de obligación no pertenece, sin embargo, al lenguaje de la ciencia de la naturaleza. A nadie se le ocurriría decir que el sol debería ponerse en el norte. Así, el concepto de deber o de obligación pertenece al lenguaje de la moral. Cuando se dice que una persona tiene un derecho, se implica que los otros tienen la obligación de reconocerlo y de respetarlo.

b) El derecho a la libertad. Locke postula el derecho a la libertad natural como un derecho fundamental, diferente esencialmente al derecho a la vida. La libertad natural, dice, consiste en ser libre de todo poder humano superior al individuo, i.e., en no ser esclavo de nadie. Consiste "en tener la libertad de seguir mi propia voluntad en todas las cosas, ... y no estar sujeto a la voluntad arbitraria, inconstante, incierta y desconocida de otro ser humano". Ahora bien, si el derecho a la libertad radica en "seguir mi propia voluntad en todas las cosas" -bajo la condición de que en la propia conducta los individuos sigan la noción del deber, que consiste en respetar los derechos de los otros-, y si el derecho a la libertad es un derecho fundamental, entonces se derivan de él muchos otros derechos que me son dados para poder seguir mi voluntad. Aunque Locke no especifica ni desarrolla los derechos que se derivan del derecho básico a la libertad, podemos inferir que son

- Ibid., IV, núm. 22. 
éstos: el derecho a seguir un credo religioso determinado por el individuo, a la libertad de conciencia para no actuar en contra de sus propios dictados, el derecho a la expresión oral y escrita, el derecho a ser escuchado y a defenderse en caso de ser acusado, el de la libertad de asamblea, etcétera. Pero en este derecho Locke también incluye la libertad de acumular propiedad en bienes materiales; sin embargo, tratará después el derecho a la propiedad como un derecho fundamental, diferente al de la libertad.

Después de Locke, otros pensadores describieron el derecho a la libertad como derecho a procurar la propia felicidad, de que hablan Jefferson ${ }^{10}$ y Kant. ${ }^{11}$ Uso el término "felicidad" en el significado que le da Kant, i.e., la satisfacción plena de todas las necesidades, deseos e inclinaciones del individuo. ${ }^{12}$ Según esto, el individuo debe tener el derecho a desarrollar libremente aquellos talentos y aptitudes que le producen satisfacción, ${ }^{13}$ como lo son, por ejemplo, el derecho al juego y al recreo, el derecho a recibir una educación técnica, humanística o científica, el derecho a ejercer un trabajo productivo que satisfaga al individuo, etcétera, o sea, todos aquellos medios que le permiten alcanzar la felicidad. Pero sobre todo, en el derecho a la libertad está implicado, como bien apunta Locke, el que nadie debe ser forzado a comportarse en contradicción con los mandatos de la propia conciencia, como lo seria, por ejemplo, el ser forzado a traicionar a un amigo, a seguir un credo político que, partiendo de la idea del derecho a la vida y libertad de todos, no puede ser justificado mediante la razón, etcétera. Son éstos los derechos que se conocen por el concepto global de derecho a la autodeterminación.

Ahora bien, el derecho a la libertad natural de que habla Locke -y del que dice que consiste en seguir la propia voluntad en todas las cosas bajo la condición de que cada uno siga la ley de la moral- parte del supuesto de que el individuo ya es, en el estado natural, un sujeto autónomo e independiente de toda influencia externa, capaz de dictarse a sí mismo y por sí solo, mediante la razón, la ley para su conducta. Pero en esta construcción del estado natural, Locke imagina a los individuos como si desde su nacimienito fuesen totalmente autarcas, aislados de todas las relaciones económico-sociales objetivas que han condicionado su voluntad desde su nacimiento. Sin embargo, del proceso de socialización dependerá lo que más tarde será "la propia voluntad", como son la

10 Th. Jefferson et al., Declaration of Independence.

11 I. Kant, Sobre el dicho vulgar: eso puede ser cierto en teorla, pero no sirve para la prdctica.

12 I. Kant, Fundamentación de la metafisica de la moralidad.

18 I. Kant, Idea de una historia universal con la intención de lograr la ciudadania mundial. 
función social del individuo, los fines a perseguir en la vida, los medios que le están permitidos usar, etcétera. Dicho en otras palabras: aun en el estado de naturaleza, los humanos no vienen al mundo en un vacio social, sino que proceden ya de una sociedad determinada: la familia.14 De la situación económica y la estructura psíquica especifica de la familia dependerá lo que más tarde será la propia voluntad. Por eso, aun en el estado de naturaleza, si hubiese existido alguna vez, el individuo está sujeto a la voluntad arbitraria e incierta de otros seres humanos. De esto resulta que tampoco en el supuesto estado natural, los individuos ejercen de una vez por todas el derecho a la libertad. De all que si bien la facultad psicológica de "seguir mi voluntad en todas las cosas" es dada a todos por igual con la vida, no lo son las condiciones reales de que parten los individuos al ejercerla. Por haber ignorado esto, Locke también ignora el poder que otros seres humanos y las relaciones socio-económicas hechas por ellos, tienen siempre sobre la voluntad del individuo. $Y$ aunque Locke especifica que la no-libertad se da solamente cuando se es esclavo, porque en esa condición la propia conducta depende de la voluntad de otro, parece no darse cuenta de que los siervos, a quienes como clase social incluye en el estado de naturaleza, dependen del poder económico y, con él, de la voluntad arbitraria del señor.

Si bien Locke y los filósofos neoliberales dirían que, a pesar de lo anterior, es un derecho a la libertad natural el poder seguir la propia voluntad sin coerción alguna, nosotros preguntamos: ¿no es verdad que nos sublevamos cuando nos percatamos de que otros quieren manipular nuestra voluntad?, ¿no es verdad que queremos poder decidir por nosotros mismos el curso de nuestras acciones? Me parece que, a pesar de haber estado sujetos al proceso de socialización y de ser conscientes de ello, en nuestra propia conciencia, deseamos y exigimos poder ejercer nuestra propia voluntad en todas las cosas, y con ello el poder determinar por nosotros mismos las ideas que hemos de aceptar, la conducta que hemos de seguir, el modo de vida que deseamos llevar, etcétera, i. e., exigimos el derecho a la autodeterminación. Ésta no es, sin embargo, una determinación que pertenezca a nuestra naturaleza, sino a nuestra conciencia de ser humanos.

De acuerdo con lo anterior, libertad significa aquil la capacidad de la persona de decidir por si misma la conducta a seguir, y autonomía significa darse a sí mismo las leyes para su conducta, aun cuando los contenidos de la voluntad sean resultado del proceso de socialización. El de-

14 T. W. Adorno et al., quienes se basan en la obra de Freud para explicar el proceso de socialización en la familia, la cual, a su vez, es "la primera agencia de la sociedad", en Der Autoritaere Charakter. 
recho a la libertad lo es entonces solamente en tanto que los individuos exigen ser tratados como personas libres y autónomas. En esto radica precisamente el ser persona. $O$ dicho de manera negativa: los individuos se sublevan contra otros, cuando éstos los tratan como objetos, como instrumentos o como medios para fines ajenos al propio. Por eso, el derecho a la libertad es el derecho a ser tratado como persona, como fin en sí mismo, del cual el individuo tiene conciencia. ${ }^{15}$ Pero aunque Locke establece este derecho como esencialmente diferente al de la vida, ambos derechos son inseparables. Quien tiene vida, también tiene derecho a ser tratado como persona.

c) El derecho a la propiedad. Bajo este término Locke y sus defensores neoliberales entienden la propiedad de bienes materiales, como son la tierra cultivable y cultivada (tarea para la cual Locke piensa y justifica la existencia de los siervos), la acumulación de bienes no corrompibles, $i$. e., oro, plata y dinero. Este derecho es postulado como un derecho fundamental y distinto a los derechos a la vida y a la libertad. Sin embargo, si aceptamos que el derecho a la vida es tal, y si aceptamos, como lo hace Locke al principio de su argumento, que para garantizar ese derecho también es necesario garantizar los medios necesarios para conservarla, la propiedad de bienes materiales es ciertamente un derecho. Pero no es, como aseguran Locke y sus sucesores, un derecho igualmente fundamental como lo es el derecho a la vida, sino un derecho derivado de aquél. Si Locke hubiera sido congruente con su premisa inicial de que el estado de naturaleza es un estado de igualdad entre los individuos, debió haber inferido que la distribución de la propiedad y de los bienes materiales debe ser igual, ya que todos por igual tienen el mismo derecho a la vida y el mismo derecho a ser tratados como personas y no como medios para el enriquecimiento, el poder o el prestigio de otros.

Desentendiéndonos del hecho de que Locke corrompe su premisa inicial al justificar una sociedad de clase basada en la propiedad privada y en la libertad de disponer de ella a capricho de los propietarios, me parece que estariamos de acuerdo en aceptar que los derechos antes mencionados son derechos que todos deseamos tener para nosotros mismos, y de los cuales esperamos sean reconocidos por todos los otros. Sin embargo, ¿qué razones existen para establecerlos y por qué deberían ser reconocidos y respetados?

Veamos: ¿cómo es posible que del factum brutum que es la vida de cada uno, se derive el derecho a la vida? ¿Y del factum brutum de desear

15 I. Kant. La idea de que el ser humano es EL fin en si mismo, y que por eso debería ser él mismo la finalidad de todas las acciones y nunca un medio para fines ajenos; compárense Fundamentación de la metafisica de la moralidad, metafisica de la moralidad, etcétera. 
ser libres se derive el derecho a la libertad? ¿En qué se basan esos derechos? Locke los fundamenta en la "ley de la naturaleza", y sostiene que mediante la razón somos capaces de conocerla. Dice: "Y la razón, que es esa ley, enseña a toda la humanidad que la consulte, que, siendo todos iguales e independientes, nadie debe dañar a otro en su vida, salud, libertad y posesiones"; ${ }^{16}$ y más adelante afirma: "Y que todos los humanos se abstengan de invadir los derechos de otros, y de hacerse daño unos a otros, y que la ley de la naturaleza sea observada." 17 Por ley de la naturaleza, Locke entiende la ley de la razón, y por ley de la razón, la "ley de Dios", 18 que nos dicta tal conducta. En el desarrollo de su tema resultará que la ley de la naturaleza es el Decálogo. Sin embargo, un estudio empírico de la naturaleza humana en sociedad nos muestra que su ley natural fáctica es la ley del más fuerte, en que la manipulación, el saqueo, la opresión, la tortura y el asesinato suceden con una regularidad constante -actos todos que contradicen la ley de la razón, de la cual Locke dice que vale ya en el estado de naturaleza. Por eso cabe preguntarse: ‘̨en qué instancia, principio, o argumentos podemos fundamentar que los humanos tienen esos derechos? ¿No es evidente acaso que los humanos han perfeccionado el uso de la razón precisamente para de hecho violar los derechos de otros más eficazmente?

Debido al hecho de que Locke trata de fundamentar los derechos en la divinidad, y debido a que imagina a los seres humanos como si existieran aislados uno de otro, y, finalmente, debido a que Locke postula la vigencia de esos derechos ya en el estado natural, su argumento es insostenible. Por el mero hecho de que esos derechos no se dan en la naturaleza, me parece un error llamarlos "derechos naturales". Son, más bien, derechos humanos.

Sin embargo, ¿qué son esos derechos? Desde la perspectiva del individuo qua sujeto que apela a su reconocimiento, éstos son una exigencia meramente subjetiva que cada uno de los individuos hace a todos los otros. Lo que aparentemente es sólo el factum brutum de la vida biológica, es, en la conciencia de cada uno de los sujetos, para sí mismos, un bien, el bien primero y fundamental, en que se basan todos los demás. Quien vive, también anhela vivir, desea tener los medios necesarios para hacerlo, anhela no estar sujeto a la voluntad, al capricho y a la arbitrariedad de otros, desea poder expresarse y ser oído, desea perseguir sus intereses, satisfacer sus inclinaciones, desarrollar sus talentos, desea determinar por si mismo su modo de vida, desea participar en la formación del orden económico, social y político en que vive -en suma,

16 J. Locke, ibid., II, núm. 6.

17 Ibid., II, núm. 7.

18 Ibid., II, núm. 8. 
desea ser feliz y generar las condiciones objetivas para lograrlo. Asf, los derechos humanos nacen de la exigencia de que la posibilidad de satisfacer todos esos deseos sea respetada por todos los demás. Esta exigencia, pues, está dirigida a los otros con quienes se convive en sociedad. Y puesto que todos y cada uno de los seres humanos, por el mero hecho de serlo, también tienen esos deseos, exigen también que la posibilidad de su realización sea respetada por los demás. El concepto de derecho nace entonces de las relaciones en que los individuos existen unos con otros. Por esto, el concepto de derecho es un concepto social; y por eso mismo, también lo es su correlato, el concepto de deber u delegación. Y puesto que el derecho a la vida y a todo lo que la hace posible, así como la libertad, es una exigencia universal, la obligación de respetarla y de cumplirla lo es también. Quien no respeta los derechos de otros, no está en condiciones de exigir respeto por los propios. La universalidad del derecho qua derecho se perdería si se hicieran excepciones. ${ }^{19}$

Sin embargo, ¿de dónde proviene esa obligación? Vimos ya que no puede proceder de la naturaleza. Pero entonces, ¿cuál es su fundamento? Veamos: El proceso de la vida de cada uno de los individuos en sociedad es esencialmente expansivo. La satisfacción plena de los intereses y deseos de cada individuo, necesariamente impedirá la satisfacción plena de los intereses y deseos de otros. Si un individuo expande su actividad a costa de otro, este último pensará que el primero ha violado uno de sus derechos; que habría sido su obligación respetarlos. ¿Pero por qué había de respetarlos? No veo otra respuesta sino la siguiente: los derechos de otros deben ser respetados porque sólo así se puede garantizar que los derechos propios no sean violados. Así, para que todos y cada uno de los individuos puedan satisfacer sus intereses y deseos por igual, es necesario que todos y cada uno pongan, para sí mismos, un limite a la posibilidad de una satisfacción plena. Una vez establecido (tácita o expresamente) ese límite, surge la idea de derecho con su correlato, la idea de obligación, como ideas universales, válidas para todos los individuos por igual.

La reflexión anterior muestra que la idea del derecho no es una idea empírica que nazca de la observación de la naturaleza humana, sino una idea de reflexión que se le da a la razón. Pero no se le da a la razón cognitiva que aprehende los fenómenos de la naturaleza, ni a la razón instrumental que conoce la adecuación de los medios que deben usarse para lograr una finalidad, sino a la razón práctica. ${ }^{20}$ Es la razón

19 No puedo discutir aquí el problema de la tesis del "derecho del más fuerte" que postula Trasimaco en la Repuiblica. El que este principio no es sostenible porque el más fuerte depende siempre del más débil ("débil" en el sentido social y polftico), lo demuestra Sócrates.

20 Acerca de la función y del trabajo de la Razón prdética, como los formula Kant, 
práctica, en efecto, la que es capaz de inteligir que para que todos los individuos puedan satisfacer en igual medida sus intereses y deseos, es necesario que todos por igual renuncien en cierta medida a esa satisfacción. Quien tiene esa intelección, sabe que su conducta ante otros no debe rebasar el límite que dañe las exigencias, i.e., los derechos de esos otros. La idea del derecho es entonces una idea de la razón práctica por la cual se regulan las relaciones externas y objetivas de la conducta de los individuos en sociedad. Es, pues, una idea reguladora, cuya función consiste precisamente en dictar el imperativo de no dañar ni agredir a nadie en su vida y libertad, y todo lo que esos derechos implican, bajo la medida de igualdad. Y debe ser la medida de igualdad porque todos son humanos por igual. Por eso, la idea del derecho implica también la de la obligación que todos los humanos tienen, en la misma medida de igualdad, unos con otros en sus relaciones económicas, sociales y políticas.

Sin embargo, al introducir la idea del deber, se modifica el sentido del concepto de libertad. Quien se comporta según la idea del derecho, ya no tendrá la "libertad de seguir su voluntad en todas las cosas", como sostienen Locke y sus adeptos. La libertad consistirá ahora en la voluntad de respetar el límite que imponen los derechos de todos los otros mediante las propias acciones. Este principio del deber es asi una ley de la razón práctica. Tal ley, no obstante, mientras sólo esté puesta en palabras (orales o escritas), no será sino eso: palabras huecas sin contenido. Para que tengan sentido, es necesario llevarlas a cabo en la práctica. Esto sólo es posible bajo dos condiciones: a) que todos y cada uno de los individuos conozcan y reconozcan, mediante la razón, la idea del derecho, y su correlato, la idea del deber, y b) que rijan su voluntad, y con ella sus acciones, por esa idea, de modo que la sociedad humana real, y en su totalidad, pase del estado de naturaleza a formar un Estado de derecho, tanto nacional como internacional.

Así pues, los derechos humanos no son naturales sino sociales, que surgen de la razón práctica. Solamente ésta puede ser su fundamento, ya que es ésta la que dicta la ley para el comportamiento ante los otros; y la dicta para llevarla a cabo en la práctica. Mientras los humanos como especie no respeten los derechos de todos los demás, dicho término será un flatus vocis. Mientras en el mundo entero se violen esos derechos, ya sea por una clase económica, social o política sobre otra, ya sea por parte de un régimen totalitario sobre su población, ya sea por parte de una nación prepotente sobre otra más débil, no podemos decir que los de-

véanse la Critica de la razón práctica, la Fundamentación de la metafísica de la moral y la Metafisica de la moral, así como todos sus otros trabajos sobre filosofia social. 
rechos humanos sean eficaces ni que se realicen para constituir un Estado -nacional e internacional- de derecho.

El problema técnico acerca de la redistribución de los bienes materiales que hacen posible el ejercicio de los derechos a la vida, la salud y la libertad, pueden ser resueltos por los tecnócratas, es decir, por economistas y sociólogos, quienes en nuestros días disponen de los conocimientos necesarios para realizar efectivamente esa repartición. La voluntad de llevar a cabo la redistribución es un problema político que depende de la voluntad de los individuos. $\mathrm{Y}$ es tarea de la filosofía politica el despertar a los ciudadanos a la conciencia de la universalidad de todos sus derechos. 